\title{
Magnetic personalities
}

\author{
Fatal Attraction: Magnetic Mysteries and \\ the Enlightenment \\ by Patricia Fara \\ Icon Books: 2005. 204 pp. $€ 9.99$
}

\section{David W. Hughes}

It is a great shame that the history of physics is not an integral part of a standard university physics education. Teaching it would provide an ideal means of dragging the laboratory- and computer-based academic physicist out into the wider world. Not only would it underline the contemporary relevance of physics, it would also civilize the subject by reconnecting it with its roots.

One requirement would be a collection of excellent introductory books on the history of physics - and Patricia Fara's Fatal Attraction is a trail-blazer for magnetism. Fara, a lecturer in the history and philosophy of science at the University of Cambridge, accurately targets the enquiring student reader. The writing is pacy, informative, riveting and unencumbered by footnotes. But the book also contains a copious reference section and draws extensively from Fara's scholarly tome Sympathetic Attractions (Princeton University Press, 1996).

Magnetism has a past rooted in the mists of antiquity. Certain types of magnetite iron oxide ore, when struck by lightning, become strongly magnetized. This natural loadstone was once greatly treasured and was first used by the Chinese in the fourth century $\mathrm{BC}$ to produce the magnetic compass, which found application both in the art of feng-shui and as a navigational device.

Fara takes us back to the times before magnetism was allied with electricity. Her main period is the Enlightenment in the seventeenth and eighteenth century, when natural philosophers and thinkers optimistically believed that the problems of society could be solved by reason and common sense. In those days, cosmic magnetic forces were the precursors of universal gravity. England's wealth and protection depended on sailors successfully navigating rough oceans, so the magnetic compass was of paramount importance. And the dawn of today's alternative medicine was heralded by the supposed hidden powers of magnets. People were happy to strap magnets to the afflicted parts of their bodies, expecting them to draw out the pain and heal toothache, rheumatism, gout, scurvy and a host of other ailments.

The story is built around three main characters: Edmond Halley, Gowin Knight and Franz Anton Mesmer.

Halley, who in 1720 became England's second Astronomer Royal, was not only a scientific polymath but also a naval adventurer who sailed the Atlantic measuring magnetic variation (the difference between true and magnetic

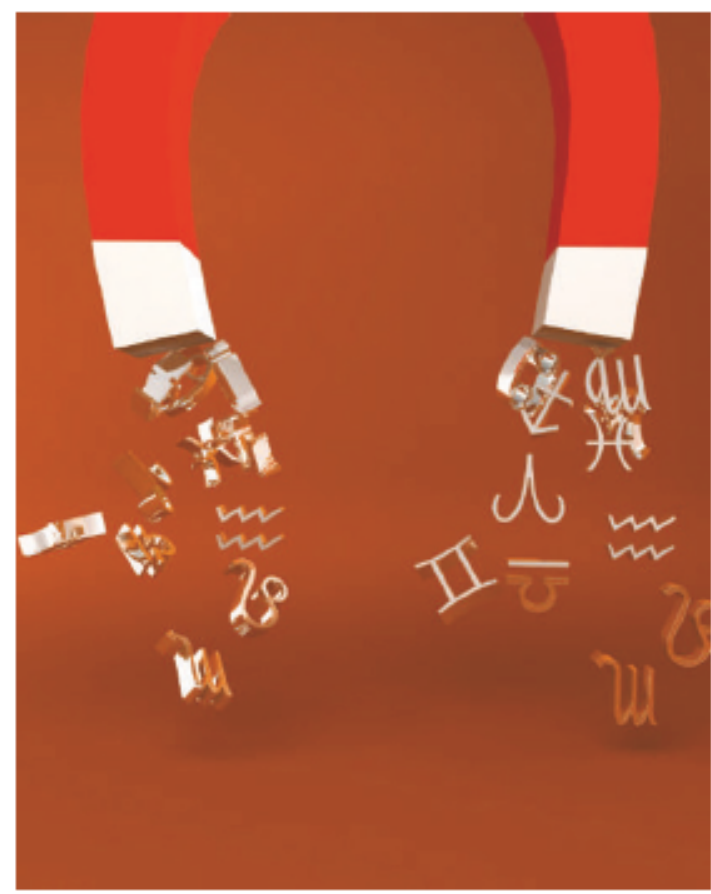

and Henry Gellibrand's discovery in $\mathbf{1 6 3 5}$ that the magnetic variation changed with time, Halley proposed that the Earth had four magnetic poles: two on the surface and two on an inner sphere, 500 miles below, that rotated at a slightly different speed.

Gowin Knight was a scientific entrepreneur from the same period whose main aim was to become rich and famous. He pioneered the production of strong artificial steel magnets and an efficient gimballed maritime air compass. He also convinced the state that science mattered — a legacy that still benefits us all.

Franz Mesmer, a Viennese physician who treated Mozart, suggested that the source of the magnetic force was a stream of invisible, weightless cartesian effluvia coursing through the minute pores of the affected substance. This cosmic magnetic fluid was not only the key to our physical well-being, he claimed, but also the

north) in the hope of finding a way to calculate longitude at sea. He was the first scientist to insist that the government pay for his instrumentation and finance a scientific mission. Halley was a great believer in speedy publication and in sharing his results (especially as they were obtained by a paid public servant).

The charts of magnetic variation drawn up by Halley were revolutionary, as he used lines to link places of equal variation. These 'halleyan lines' (now known as isogonics) have become a ubiquitous feature of modern meteorological charts. Spurred on by William Gilbert's textbook on geomagnetism from 1600 modus operandi of astrological influence. Moving to Paris in 1778, Mesmer then creamed off the wealthiest patients, causing such annoyance to competing doctors that he was eventually forced to flee the country.

Fara ends her excellent historical review by briefly relating how the magic of magnetism was somewhat spoiled by Michael Faraday. Britain's first professional scientist founded electromagnetism, one of the cornerstones of the modern consumer society, and now nearly every aspect of it is well understood. David W. Hughes is professor of astronomy, University of Sheffield, Sheffield S37RH, UK.

\section{A poisoned reputation}

\section{Between Genius and Genocide: The \\ Tragedy of Fritz Haber, Father of Chemical Warfare \\ by Daniel Charles \\ Jonathan Cape: 2005.313 pp. $€ 20$ \\ Published as Master Mind by Ecco Press in the US (\$24.95).}

\section{John Comwell}

Fritz Haber will be forever linked with the Haber-Bosch recipe, which produces plentiful and cheap supplies of ammonia. Yet he was one of the greatest chemists of the twentieth century and was the founding father of the industrial-military complex. The story of his life, which has all the ingredients of a Thomas Mann novel, is a tale of scientific genius in the service of the German fatherland. Haber was a
Jew who adopted Christianity to advance his career prospects but instead became a victim of the Nazis. He was an outstanding hero of science but stood accused of war crimes.

The process for which Haber is best known is the synthesis of ammonia from two plentiful gases in nature: hydrogen and nitrogen. $\mathrm{He}$ collaborated with Carl Bosch to discover, after some 4,000 trials, an ideal catalyst composed of iron and oxides of aluminium, calcium and potassium. The process is virtually unchanged to this day. The discovery culminated in the production of prodigious quantities of artificial nitrogen fertilizer, which allowed the global population to rise to 6 billion from below its estimated upper limit of 3.6 billion. As a result, Haber richly merits consideration as one of the greatest figures of the past millennium. 